Aus der Bakteriologischen Abteilung des Reichsgesundheitsamtes in Berlin.

\title{
Ueber den Nachweis von Azeton im Harn.
}

\author{
Von Dr. H. Citron.
}

Ueber die Wichtigkeit des Azetonnachweises im diabetischen Harn ist kaum ein Wort zu verlieren, doch läßt die Methodik mancles zu wünsclien übrig. Azetonuntersucliungen im Harn dürften streng genommen nur im Destillat desselben angestellt werden; hierin abe liegt eine Scliwierigkeit, welcher der Praktiker, nicht zum Vorteil der Exaktheit, meist aus dem Wege, gelit. In der Regel wird die nicht sehr zuverlässige, anch wenig empfindliclıe Legalsclte Nitroprussidprobe mit dem Harn selbst angestellt. Der von mir konstruierte und in der Bakteriologischen Abteilung des Reichsgesundheitsamtes mehrere Monate erprowte Apparat ${ }^{1}$ ) macht den Destillationsprozeß zu einem höchst einfachen, in der Sprechstunde in wenigen Minuten ausfüh rbaren Verfahren. Der Apparat besteht aus einer gläsernen Hohlkugel von zirka $250 \mathrm{ccm}$ Fassung, die oben offen ist und nach unten in einen geschlossenen Stiel ausläuft. dem ein tellerartiges Schüsselchen angeschmolzen 'ist. Zum Gebrauch werden $50 \mathrm{ccm}$ Harn in ein Becherglas gegossen, das in einem vorher bereits zum Sieden erhitzten Wasserbade steht. Die mit recht kaltem Wasser gefüllte Kugel wird auf das Becherglas gesetzt, das Ganze zirka 5 Minuten gekocht. Das Schüsselchen $m u B$ vor dem Gebrauch gut abgespült und getrocknet werden. - Nach zirka 5 Minuten - falls sich auf

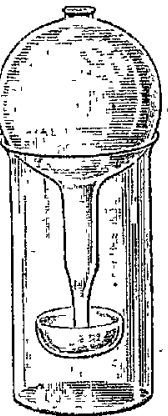

dem Schüsselchen noch zu wenig Flüssigkeit kondensiert hat, kann man auch nocl ${ }^{2}$ etwas länger erwärmen _- nimmt man diê Kugel herunter und saugt mit einer Pipette die in Schüsselclien befind. liche Flüssigkeit auf. Zuvor hat nıan in einem Schälchen zirka $2 \mathrm{ccm}$ einer 3\% igen Jod-Jodkaliumlösung mit $1 \mathrm{ccm}$ eit1er $10 \%$ igen Natronlauge gemischt. Man fügt etwa $1 \mathrm{ccm}$ Destillat zu. Bei Anwesenlreit von Azeton entsteht fast augenblicklich eine weiße Trübung beziehungsweise ein Niederschlag, und es entwickelt sich starker. Geruch naclı Jodoform. Die Empfindlichkeit der Probe, in dieser Weise angestellt, ist enorm. Sie fällt in einem Urin, der auf 50 ccm Harn $0,1 \mathrm{ccm}$ einer $1 \%$ igen wäßrigen Azetonlösung ent thält, also bei einem Azetongehalt von 1 zu 50000 , nocl positiv aus. Natürlich steht nichts im Wege, das Destillat aucl für andere Azeton. proben z. B. für die sehr empfehlenswerte Penzoldtsclie Nitrobenzaldehydreaktion, zu verwenden. Der Apparat eignet sich übrigens niclit nur für den Nachweis von Azeton, sondern auch für andere flüchtige Stoffe, z. B. Formaldehyd und Azetaldelıyd (Milchsäırre). Diesbezügliche Versuche sind noclir inI Gange und dem AbschluB nahe. 